\title{
CONECTORES EN GRIEGO ANTIGUO
}

\author{
Connectors in ancient greek
}

Roberto Morales Harley*

\begin{abstract}
RESUMEN
Con base en las clasificaciones de Martín y Portolés (2000) y de Calsamiglia y Tusón (2008) para los marcadores discursivos y para los conectores en lengua española, el trabajo propone la siguiente tipología de los conectores en griego antiguo: 1. Aditivos (1.1. Los que añaden un argumento de igual valor, 1.2. Los que añaden un argumento de mayor valor), 2. De base causal (2.1. Finales, 2.2. Causativos, 2.3. Consecutivos) y 3. Contraargumentativos (3.1. Los que introducen un contraargumento débil, 3.2. Los que introducen un contraargumento fuerte). De este modo, se ofrece una alternativa para el estudio de conjunciones, adverbios, locuciones y, especialmente, partículas en griego antiguo. Como resultado, se identificaron, en la Ilíada IX, un total de 8 ejemplos conectores aditivos ( 3 con argumentos de igual valor y 5 con argumentos de mayor valor), 14 ejemplos de conectores de base causal (2 finales, 9 causativos y 3 consecutivos) y 11 ejemplos de conectores contraargumentativos ( 9 con contraargumentos débiles y 2 con contraargumentos fuertes).

Palabras clave: conectores, marcadores discursivos, argumentación, griego antiguo.
\end{abstract}

\section{ABSTRACT}

On the basis of Martín and Portolés' (2000) and Calsamiglia and Tusón's (2008) classifications for discourse markers and for connectors in Spanish, the paper proposes the following typology of ancient Greek connectors: 1. Additive (1.2. Those who add an equally valuable argument, 1.2. Those who add a more valuable argument), 2. With a causal basis (2.1. Final, 2.2. Causative, 2.3. Consecutive), and 3. Counter argumentative (3.1. Those who introduce a weak counter argument, 3.2. Those who introduce a strong counter argument). Thus, it offers an alternative for the study of conjunctions, adverbs, fixed expressions and, specially, particles in ancient Greek. As a result, a total of 8 examples of additive connectors ( 3 with equally valuable arguments and 5 with more valuable arguments), 14 examples of connectors with a causal basis (2 finals, 9 causatives and 3 consecutives), and 11 examples of counter argumentative connectors (9 with weak counter arguments and 2 with strong counter arguments) were identified in the Iliad IX.

Key Words: connectors, discourse markers, Argumentation, ancient Greek.

\footnotetext{
Universidad de Costa Rica. Escuela de Filología, Lingüística y Literatura. Costa Rica.

Correo electrónico: roberto.moralesharley@ucr.ac.cr

Recepción: 26/10/16. Aceptación: 29/11/16.
} 


\section{Introducción}

La sintaxis constituye uno de los temas de mayor complejidad (quizás solo superado por la morfología verbal) en el estudio de la lengua griega. Este ámbito ha sido objeto de análisis, desde la perspectiva tradicional de la gramática, por más de dos mil años (Crespo, 2003: 32). Sin embargo, trabajos como los de Kroone (1998), López (1999) y Cerdas (2015) han demostrado la viabilidad de análisis de textos clásicos mediante teorías lingüísticas modernas.

Uno de los puntos concretos en que la sintaxis del griego antiguo puede verse enriquecida es, según la presente propuesta, complementar (lo que no implica abandonar) la tipología de clases de palabras, tales como conjunción, adverbio o partícula, con una categorización por unidades funcionales, por ejemplo, marcadores discursivos y conectores.

\footnotetext{
La sintaxis griega, heredera de la sintaxis griega de Dionisio Tracio y de los estudiosos posteriores de la Antigüedad, atiende a las clases de palabras de manera exclusiva o, al menos, predominante. La sintaxis moderna, sin desdeñar el estudio de las clases de palabras, toma también como unidad de descripción las unidades funcionales en la oración o en el enunciado (Crespo, 2003: 38).
}

Entre las distintas clases de palabras que establece la sintaxis griega, las partículas son las que presentan un grado de dificultad más elevado. Pese a que todas las conjunciones, las preposiciones y los adverbios son partículas (Martín y Portolés, 2000: 4055), no todas las partículas son adverbios, preposiciones o conjunciones. Existen partículas, al menos en griego antiguo, cuya categoría gramatical es solamente esa: partículas. Esto ha llevado a los especialistas a postular su definición en los siguientes términos: "hiperclase de palabras no flexivas" (Rodríguez, 1992: 681-704).

En aras de una mayor comprensión de tales palabras, se ha recurrido a modelos lingüísticos modernos para su análisis. Por ejemplo, Durán (2000) organiza las partículas griegas a partir de las funciones del lenguaje de Jakobson: expresiva (emisor), conativa (destinatario), poética (mensaje), referencial (contexto), fática (canal) y metalingüística (código). Así, à $\lambda \lambda \dot{\alpha}$, con valor exhortativo ( $i$ ea!), corresponde a la función conativa; toí (ciertamente), a la función fática; y ò $q \alpha \rho \rho$, con valor correctivo (más bien), a la función metalingüística.

Si bien se centra solo en una partícula, al ofrecer un enfoque desde la función discursiva, merece especial mención el trabajo de Martín (1993), para quien, $\delta \varepsilon ́$ (por otra parte) se puede usar "para indicar la alternancia de participantes en el diálogo o la aparición sucesiva de personajes dentro del drama o de la narración", "para establecer una nueva fase en el discurrir de la narración o de la argumentación" o "para introducir una o varias expresiones que interrumpen la línea principal del discurso con el objeto de ofrecer información parentética, adicional o explicativa" (Martín, 1993: 230). Según dicho modelo, las partículas griegas se han de analizar, no solo como parte de la oración en la que aparecen, sino también como parte del texto al que pertenecen.

La investigación tradicional acerca de las partículas griegas -como la de las sintaxis de las lenguas antiguas en general- ha estado confinada durante largo tiempo al análisis de oraciones aisladas extraídas fuera de su contexto. La introducción de la perspectiva funcional del discurso viene a ofrecer nueva luz a ésta y otras cuestiones hasta ahora consideradas problemáticas o insolubles incluso (Martín, 1993: 222).

Una sistematización de los marcadores discursivos no es tarea fácil (Martín y Portolés, 2000: 4056). No obstante, incluso una propuesta parcial, que incorpore al menos las partículas de mayor uso en lengua griega, como $\delta \varepsilon ́$ (por otra

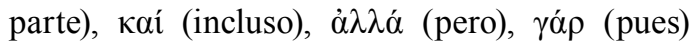
(cfr. Martín, 1993: 223) y se base en modelos establecidos, como Martín y Portolés (2000) y Calsamiglia y Tusón (2008), puede ofrecer un punto de partida para nuevas investigaciones.

\section{Marcadores discursivos y conectores en español}

En primer término, conviene hacer una serie de precisiones conceptuales sobre los 
términos clave del análisis: discurso, marcador discursivo, conector. Para el discurso, Martín y Portolés (2000: 4057) señalan "la acción y el resultado de utilizar las distintas unidades que facilita la gramática de una lengua en un acto concreto de comunicación", mientras que Calsamiglia y Tusón (2008: 1; itálica del original), prefieren "hablar de una práctica social, de una forma de acción entre las personas que se articula a partir del uso lingüístico contextualizado, ya sea oral o escrito". En ambos casos, el componente gramatical del discurso se ve complementado por un componente pragmático, entendida la pragmática como "el estudio de los principios que regulan el uso del lenguaje en la comunicación" (Escandell, 2008: 15-16). Además, en la segunda definición se incluye, como una posibilidad, el uso escrito, que, en el caso de las lenguas clásicas como el griego, es el único con que se cuenta.

Desde esta perspectiva, se define los marcadores discursivos bien como "unidades lingüísticas invariables”, cuya función, más que sintáctica, es de índole discursiva: "guiar, de acuerdo con sus distintas propiedades morfosintácticas, semánticas y pragmáticas, las inferencias que se realizan en la comunicación" (Martín y Portolés, 2000: 4057), bien como "piezas lingüísticas que relacionan de forma explícita segmentos textuales, sean enunciados o secuencias de enunciados, estableciendo entre ellos diversas relaciones semánticas" (Calsamiglia y Tusón, 2008: 235).

Finalmente, los conectores son un tipo de marcadores discursivos que "vincula semántica y pragmáticamente un miembro del discurso con otro miembro anterior" (Martín y Portolés, 2000: 4093) o que "sirven para poner en relación lógico-semántica segmentos textuales, sean enunciados o conjuntos de enunciados" (Calsamiglia y Tusón, 2008: 237). Dicha relación es expresada por el conector, pero preexiste "en la mente de los interlocutores, en su conocimiento compartido" (Calsamiglia y Tusón, 2008: 235).

Para una clasificación de los marcadores discursivos en español, se han seguido dos modelos. El primero de ellos, de Martín y Portolés (2000: 4080-4199; adaptación), establece cinco tipos:

\section{Estructuradores de la información}

1.1. Comentadores: pues, pues bien, así las cosas...

1.2. Ordenadores: en primer lugar/en segundo lugar; por una parte/por otra parte; de un lado/de otro lado...

1.3. Digresores: por cierto, a todo esto, a propósito...

\section{Conectores}

2.1. Aditivos: además, encima, aparte, por añadidura, incluso/inclusive, es más...

2.2. Consecutivos: pues, así pues, por tanto, por consiguiente/consiguientemente/ consecuentemente, por ende, de ahí, en consecuencia, de resultadas, así, entonces...

2.3. Contraargumentativos: en cambio, por el contrario, al contrario, por contra, antes bien, sin embargo, no obstante, con todo, empero, ahora bien, ahora, eso sí...

\section{Reformuladores}

3.1. Explicativos: o sea, es decir, esto es, a saber...

3.2. De rectificación: mejor dicho, mejor aún, más bien...

3.3. De distanciamiento: en cualquier caso, en todo caso, de todos modos...

3.4. Recapitulativos: en suma, en conclusión, en definitiva, en fin, al fin y al cabo...

\section{Operadores argumentativos}

4.1. De refuerzo argumentativo: en realidad, en el fondo, de hecho...

4.2. De concreción: por ejemplo, en particular... 


\section{Marcadores conversacionales}

5.1. De modalidad epistémica: claro, desde luego, por lo visto...

5.2. De modalidad deóntica: bueno, bien, vale...

5.3. Enfocadores de la alteridad: hombre, mira, oye...

5.4. Metadiscursivos conversacionales: bueno, eh, este...

El segundo modelo, de Calsamiglia y Tusón (2008: 236-238; adaptación), propone cuatro tipos:

\section{Marcadores que contribuyen a la organización global del texto}

1.1. Iniciadores: para empezar, antes que nada, primero de todo...

1.2. Distribuidores: por un lado, por otro; por una parte, por otra; éstos, aquellos...

1.3. Ordenadores: primero, en primer lugar, en segundo lugar...

1.4. De transición: por otro lado/parte, en otro orden de cosas...

1.5. Continuativos: pues bien, entonces, en este sentido, el caso es que, a todo esto...

1.6. Aditivos: además, igualmente, asimismo...

1.7. Digresivos: por cierto, a propósito...

\subsection{Espacio-temporales}

1.8.1. De anterioridad: antes, hasta el momento, más arriba, hasta aquí...

1.8.2. De simultaneidad: en este momento, aquí, ahora, al mismo tiempo, mientras, a la vez...
1.8.3. De posterioridad: después, luego, más abajo, seguidamente, más adelante...

1.9. Conclusivos: en conclusión, en resumen, en suma, en resumidas cuentas, total...

1.10. Finalizadores: en fin, por fin, por último, para terminar, en definitiva...

2. Marcadores que introducen operaciones discursivas

2.1. De expresión de punto de vista: en $\mathrm{mi}$ opinión, a mi juicio, a nuestro entender, desde mi punto de vista, a mi parecer, tengo para mí, por lo que a mí respecta...

2.2. De manifestación de certeza: es evidente que, es indudable, todo el mundo sabe, nadie puede ignorar, es incuestionable, de hecho, en realidad, está claro que...

2.3. De confirmación: en efecto, por supuesto, desde luego, por descontado, efectivamente, claro...

2.4. De tematización: respecto a, a propósito de, por lo que respecta a, en cuanto a, referente a, con referencia a, en lo que concierne, en/por lo que se refiere a...

2.5. De reformulación, explicación o aclaración: esto es, es decir, en otras palabras, quiero decir, o sea, a saber, bueno, mejor dicho, en particular, en concreto...

2.6. De ejemplificación: por ejemplo, a saber, así, en concreto, pongamos por caso, sin ir más lejos...

2.7. De cita: según, para, como dice...

\section{Conectores}

3.1. Aditivos o sumativos: y, además, encima, después, incluso; igualmente, asimismo, también, tal como, del mismo modo; ni, tampoco... 


\subsection{Contrastivos o contraaargumentativos:}

3.2.1. De oposición: pero, en cambio, sin embargo, ahora bien...

3.2.2. De sustitución: sino, en lugar/vez de, por el contrario, antes bien, contrariamente...

\subsubsection{De restricción: excepto si, a no ser que...}

3.2.4. De concesión: de todos modos, sea como sea, en cualquier caso, a pesar de, no obstante, con todo, aun así, después de todo, así y todo, con todo (y con eso)...

\subsection{De base causal:}

3.3.1. Causativos: a causa de ello, por eso, porque, pues, puesto que, ya que, dado que, por el hecho de que, en virtud de, gracias a...

3.3.2. Consecutivos: de ahí que, pues, luego, por eso, de modo que, de ello resulta que, así que, de donde se sigue, así pues, por (lo) tanto, de suerte que, por consiguiente, en consecuencia, en efecto, entonces...

3.3.3. Condicionales: si, con tal de que, cuando, en el caso de que, según, a menos que, siempre que, mientras, a no ser que, siempre y cuando, sólo que, con que...

3.3.4. Finales: para que, a fin de que, con el propósito/objeto de, de tal modo que...

3.4. Temporales: cuando, de pronto, en ese momento, entonces, luego, más tarde, mientras tanto, una vez, un día, en aquel tiempo, de repente, en seguida...

3.5. Espaciales: enfrente, delante, detrás, arriba, abajo, al fondo, a la derecha, a la izquierda, a lo largo, a lo ancho, por encima...

4. Marcadores que son eminentemente interactivos y estructuradores del discurso oral

4.1. De apelación: ¡eh!, ¡oye!, ¡usted!, ¡señora!, ¡joven!...
4.2. De demanda de confirmación o de acuerdo: ¿eh?, ¿verdad?, ¿sí o no?, ¿no?, ¿me entiendes?, ¿me sigues?, ¿sabes qué quiero decir o no?, ¿vale?, ¿ves?, ¿oyes?, ¿sabes?..

4.3. De advertencia: mira, oiga, ojo, cuidado, fíjate...

4.4. Reactivos de acuerdo: bueno, perfecto, claro, sí, bien, vale, de acuerdo, sí; exacto, evidente, okey, ya, perfectamente...

\subsection{Estimulantes: venga, va...}

4.6. Iniciativos: bueno, bueno pues, mira, veamos, mire usted, a ver, vamos a ver, ¿sabes qué?..

4.7. Reactivos: ¡hombre!, ¡mujer!, tío, vaya, es que...

4.8. Reactivos de desacuerdo: bueno, pero; vaya, no, tampoco, nunca, en absoluto, qué va, para nada, por favor; anda ya, ni hablar, ni modo...

4.9. De duda: bueno, o sea, este, esto, eee, mm...

4.10. De aclaración, corrección o reformulación: o sea, mejor dicho, quiero decir, bueno...

4.11. De atenuación: bueno, un poco, yo diría, como, como muy, de alguna manera, en cierto modo, digamos...

4.12. De expresividad: ¡no me digas!, ¿ah, sí?, ¡oh!, ¡uuuy!, ¡qué horror!...

4.13. De tránsito: bueno..

4.14. Continuativos: luego, después, entonces, así pues, conque, total, pues, pues nada, así que...

4.15. De finalización y conclusión: y tal, y eso, y todo; venga, hala, hale, bueno...

4.16. De cierre: y ya está, nada más, eso es todo... 


\section{Adverbios, conjunciones, partículas y locuciones en griego antiguo}

Sobre la base de una revisión de la Gramática griega de Berenguer (2002), se brinda la siguiente clasificación de adverbios, conjunciones de coordinación, conjunciones de subordinación, partículas y otras locuciones que entran dentro de las categorías previas. La lista incluye únicamente aquellas formas que, por su sentido, podrían entrar dentro del grupo de los conectores.

\section{Adverbios}

1.1. De afirmación: $\tilde{\eta}$ (seguramente), $\mu \alpha \dot{\alpha} \lambda \iota \tau \alpha$ (exactamente), $\tau$ oí (en verdad)

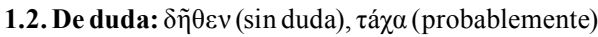

1.3. De modo: $̋ ّ \varsigma(a s i ́)$

1.4. De lugar: $\check{\varepsilon} v \theta \varepsilon v$ (de ahí)

1.5. De tiempo: $\check{\varepsilon} v \theta \alpha$ (entonces), $\tau o ́ \tau \varepsilon$ (entonces)

2. Conjunciones

2.1. Conjunciones de coordinación

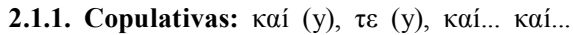
(no solo... sino también...), $\tau \varepsilon \ldots \tau \varepsilon \ldots$ (no solo... sino

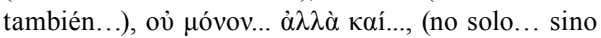

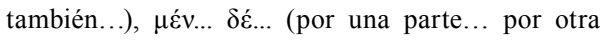
parte...), ov้ $\tau \varepsilon$ (ni)

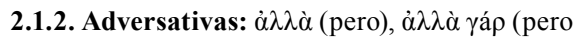

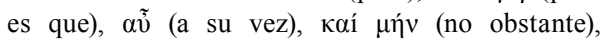

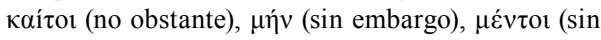
embargo), ö $\mu \omega \varsigma$ (y sin embargo)

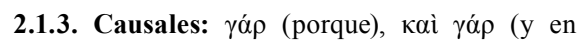
efecto)

2.1.4. Consecutivas: $\alpha \propto \rho \alpha \quad$ (pues), $\delta \eta ́$

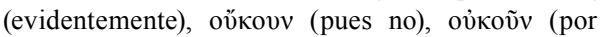

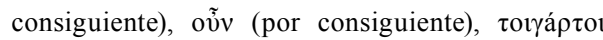

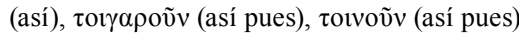

\subsection{Conjunciones de subordinación}

2.2.1. Finales: i๊ $\alpha \alpha$ (para que), ő $\pi \omega \varsigma$ (para que), ö $\pi \omega \varsigma \not \alpha \nu$ (para que), $\omega \varsigma$ (para que)

2.2.2. Causales: $0 ̋ \tau l$ (porque), $\delta$ tó $\tau l$ (porque), $\dot{\omega} \varsigma$

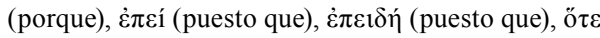
(puesto que)

2.2.3. Consecutivas: $̋ \sigma \tau \varepsilon$ (de modo que), $\omega \varsigma$ (de modo que)

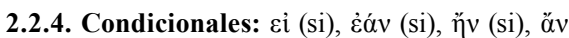

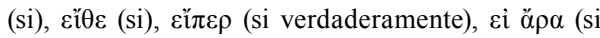

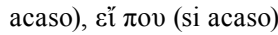

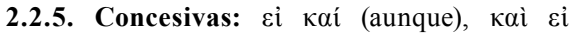

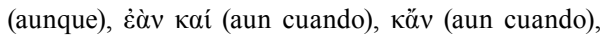

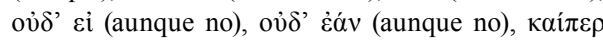
(por más que), $\pi \lambda \eta \dot{v}$ (excepto)

2.2.6. Temporales: $\dot{\varepsilon} \pi \varepsilon i ́$ (después que), $\dot{\varepsilon} \pi \varepsilon 1 \delta \eta ்$

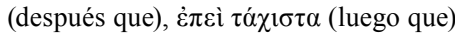

3. Partículas: $\alpha \rho \rho \alpha$ (entonces), $\gamma \varepsilon ́$ (por lo menos),

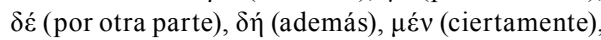
$\tau \varepsilon(\mathrm{y})$

\section{Ejemplos literarios}

El objetivo de esta sección es revisar los usos literarios de las formas incluidas en el apartado 3, con el fin de elaborar una tipología para el griego antiguo sobre la base de las clasificaciones citadas en el apartado 2.

El texto literario elegido es el libro IX de la Ilíada, conocido desde la Antigüedad como $\pi \rho \varepsilon \sigma \beta \varepsilon i ́ \alpha$ (embajada), por relatar el esfuerzo de los embajadores Odiseo, Fénix y Áyax en procura de traer de vuelta al combate en la guerra de Troya a Aquiles (quien se había apartado de su bando enojado porque Agamenón le había quitado a su compañera Briseida). 
La embajada constituye un entorno apropiado para el análisis del discurso, puesto que, si ya los discursos en estilo directo son característicos de la épica homérica (López, 1988: 62), estos son aún más frecuentes en la embajada. Además, si los discursos de embajada son fuente para el estudio de marcadores discursivos, lo son en mayor grado para el abordaje de conectores, especialmente de aquellos que "se especializan en adjudicar una orientación argumentativa, es decir, dirigida hacia una conclusión a partir de los enunciados puestos en contacto" (Calsamiglia y Tusón, 2008: 236).

Los discursos presentes en la embajada de la Ilíada forman parte de una argumentación, entendida como "un acto de habla complejo cuyo propósito es contribuir a la resolución de una diferencia de opinión o una disputa" (Van Eemeren y Grootendorst, 2002: 29). Odiseo, Fénix y Áyax opinan que Aquiles debería volver a la guerra, si bien por distintas razones: el primero remite el mensaje oficial de Agamenón y justifica su punto de vista mediante en énfasis en los regalos que el rey ofrece al héroe; el segundo, de una forma más familiar, aconseja a quien fuera objeto de su crianza por medio de la introducción de varios relatos de carácter didáctico y paradigmático; finalmente, el tercero interpela, incluso en un tono descortés, a quien considera su igual, su compañero de armas.

Por su parte, Aquiles es de la opinión de que no vale la pena seguir peleando, pues el costo de exponer la vida con mucho sobrepasa el beneficio de ser objeto de reconocimiento social, especialmente si el honor se puede quitar con la misma facilidad con que se entrega. Aquiles da tres respuestas: a Odiseo, que se marchará; a Fénix, que decidirá si se marcha o no; a Áyax, que no se marchará, pero tampoco peleará, hasta que la situación no sea crítica (para mal del propio Aquiles, este punto coincidirá con la muerte de su mejor amigo, Patroclo).

Seguidamente, se ofrecen 33 ejemplos, que incluyen conectores aditivos, de base causal y contraargumentativos.

1. Aditivos
1.1. Los que añaden un argumento de igual valor

1.1.1. $\delta \varepsilon ́$ (por otra parte)

La partícula $\delta \dot{\varepsilon}$ presenta los siguientes valores (Pabón, 1999: 128): adversativo (sino), copulativo (y), ilativo (pues). Uno de sus usos más frecuentes es en correlación: $\mu \varepsilon \grave{\varepsilon} v$ (por una parte)... $\delta \dot{~}$ (por otra parte). En tales casos, puede funcionar, no solo como un "ordenador" (Martín y Portolés, 2000) o un "distribuidor" (Calsamiglia y Tusón, 2008), sino también como conector que añade un argumento de igual valor en una "argumentación múltiple" (aquella en la cual, "las argumentaciones únicas que la constituyen son, en principio, defensas alternativas del mismo punto de vista"; Van Eemeren y Grootendorst, 2002: 95). En el corpus seleccionado ${ }^{1}$, se hallaron tres ejemplos de esta función (1-3).

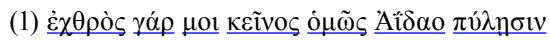

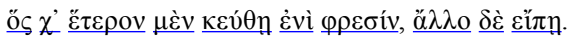

En efecto, para mí es odioso igual que las puertas del Hades

aquel que, por una parte, oculta una cosa en sus mientes y, por otra parte, dice otra.

(Il. IX, 312-313)

En su primera respuesta, Aquiles caracteriza a Agamenón como $\underline{\kappa i ̃ v o \zeta ~(o d i o s o) ~}$ y justifica su afirmación con dos argumentos: porque esconde sus verdaderas intenciones y porque miente al hablar. La proximidad entre ambas ideas queda marcada por el empleo de las partículas correlativas. De este modo, se evidencia que la segunda justificación tiene una fuerza argumentativa igual a la de la primera.

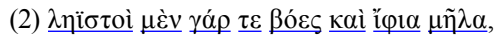

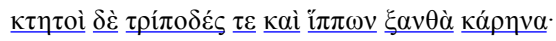

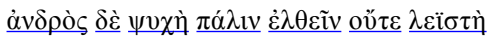

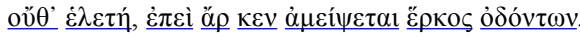


Por una parte, son botines de guerra los bueyes y las fuertes ovejas;

por otra parte, son bienes adquiribles los trípodes y las amarillas cabezas de caballos;

pero alcanzar de nuevo la vida de un hombre ni es un botín de guerra

ni un bien que puede ser cogido, después de que abandona el cerco de los dientes.

(Il. IX, 406-409)

Esta cita pertenece al mismo discurso que la anterior. Ahora se establece una oposición entre la vida, por una parte, y los botines de guerra y los bienes adquiribles, por otra. Mientras que aquella es considerada como única en razón de la imposibilidad de recuperarla una vez que se ha perdido, estos, por igual, se pueden ganar, perder y volver a ganar muchas veces. En el contexto griego, Briseida es considera un

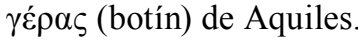

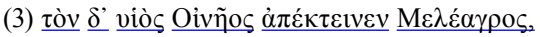

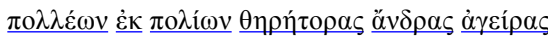

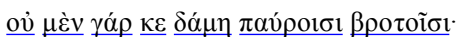

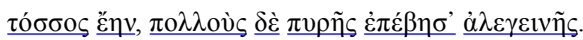

Pero a este lo mató Meleagro, el hijo de Eneo,

habiendo reunido de muchas ciudades hombres cazadores

y perros; pues, por una parte, no habría sido sometido por pocos mortales,

$y$, por otra parte, era tan grande que a muchos hizo subir a la dolorosa pira.

(Il. IX, 543-546)

Fénix, en su discurso, también recurre a la citada partícula. Como parte de su estrategia para convencer a Aquiles, le cuenta la historia de Meleagro, un contraejemplo de un héroe que volvió a la lucha cuando ya era muy tarde para que le tributaran honores, con la intención de que Aquiles lo haga en el momento en que aún es posible el reconocimiento. Para el héroe épico griego, $\tau \iota \mu$ (honor) es la motivación para tomar parte en empresas bélicas.

En concreto, la cita alude al jabalí enviado como castigo por la diosa Ártemis, ofendida por el olvido del rey que no le brindó el debido sacrificio, a fin de provocar mayor destrucción durante el enfrentamiento entre etolos y curetes. Meleagro fue capaz de someterlo a causa de su excelencia guerrera, la cual es enfatizada mediante la doble explicación: en un caso hipotético, muchos hombres no habrían conseguido vencerlo; en un dato real, el jabalí ya había derrotado a muchos hombres.

\subsection{Los que añaden un argumento de mayor valor}

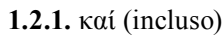

En griego, kaí (Pabón, 1999: 319), como conjunción, puede tener valor copulativo (y), adversativo (a pesar de), disyuntivo (o) e ilativo (pues); y, como adverbio, puede tener valor temporal (cuando) y modal (asimismo). En su forma adverbial, es posible traducirlo como "también" o "incluso". Este último sentido es, precisamente, el que funciona para añadir un argumento de mayor valor. En el corpus, se identificaron cinco ejemplos de dicho uso (4-8).

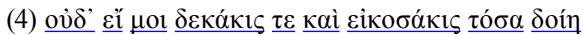

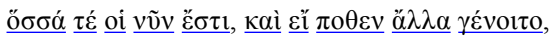

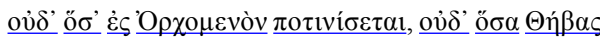

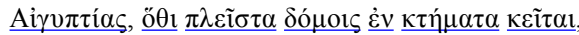

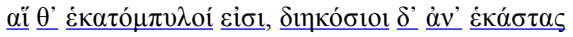

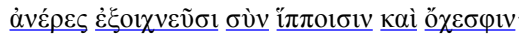

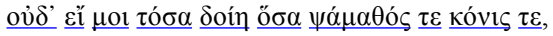

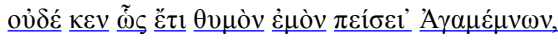

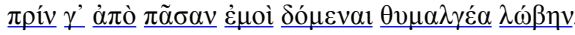


$\mathrm{Ni}$ siquiera si diez veces, o incluso veinte veces, tanto me diera

cuanto ahora tiene; si de alguna parte otras cosas aparecieran:

cuanto ingresa a Orcómeno, cuanto a la egipcia Tebas,

donde yacen numerosas riquezas en las casas,

la ciudad de las cien puertas, a través de cada una de las cuales

salen doscientos hombres con caballos y carros;

ni siquiera si tanto me diera cuanto hay de arena y de polvo;

ni aun así podría Agamenón persuadir mi ánimo,

hasta que no me compense por toda la afrenta que me aflige el ánimo.

\section{(Il. IX, 379-387)}

La primera respuesta de Aquiles es la más enfática en su negativa. El héroe rechaza categóricamente la propuesta de Agamenón, puesto que este pretende compensar por la vía material una ofensa cuyos efectos adversos son de índole inmaterial. En la terminología griega, Agamenón ofrece $\gamma \varepsilon ́ p \alpha \varsigma$ (botín) para resarcir a Aquiles en cuanto a $\tau \mu$ ஸ́ (honor). Si bien para los griegos aquella puede servir como manifestación de esta, Aquiles se centra en su volatilidad: así como las cosas materiales van $\mathrm{y}$ vienen, del mismo modo, el reconocimiento que ellas procuran no es para siempre. Bajo tal razonamiento, la cantidad de regalos propuesta por Agamenón es insuficiente, no cuantitativamente (la enumeración de carácter hiperbólico deja bien claro que no habría ningún número suficiente), sino cualitativamente.

El conector interrelaciona el primer argumento (diez veces esa cantidad no sería suficiente) con el segundo argumento (veinte veces esa cantidad no sería suficiente). El hecho de que el segundo de estos argumentos sea de mayor valor resulta particularmente evidente con el empleo de los adverbios de número: $\delta \varepsilon \kappa \alpha ́ k 1 \varsigma$

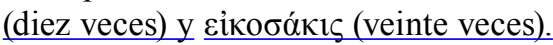

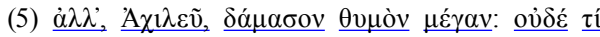
$\underline{\sigma \varepsilon} \chi \rho \grave{\eta}$

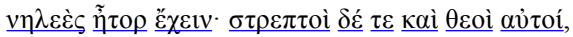

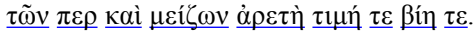

Pero, Aquiles, doma tu ánimo orgulloso; no es necesario que tú tengas así

el corazón implacable, pues incluso son flexibles los mismos dioses,

de quienes sin duda aún mayores son la virtud, el honor y la fuerza.

(Il. IX, 496-498)

Un argumento de doble jerarquía (aquel que "permite basar una jerarquía puesta en duda en una admitida; por eso, presta una ayuda muy estimable cuando se trata de justificar reglas de conducta"; Perelman y Olbrechts-Tyteca, 1994: 523) es lo que se encuentra en el discurso de Fénix. El argumento es el siguiente: los dioses son superiores a los hombres; los dioses pueden ser movidos con palabras; entonces, los hombres pueden ser movidos con palabras. La superioridad de los dioses con respecto a los hombres es la jerarquía admitida, mientas que la transposición de propiedades desde un superior hacia un inferior es algo que podría ponerse en duda.

La intención del argumento es brindar una regla de conducta: que Aquiles desista en su orgullo, pues los dioses, que tendrían más motivos para mostrarse orgullosos, también saben ceder. En este sentido, el conector añade un argumento cuyo mayor valor, si bien no es delimitado con números concretos, sí es claro en el contexto cultural griego.

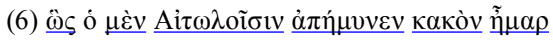

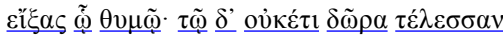

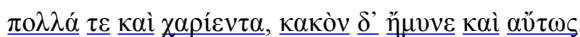


Así él defendió a los etolos en el mal día,

cediendo a su ánimo; y ya no le concedieron los regalos

numerosos y gratos, e incluso así ayudó en el mal.

(Il. IX, 597-599)

Nuevamente es Fénix quien introduce este conector. En la citada narración sobre Meleagro, se menciona que este héroe, habiendo decidido ya muy tarde pelear en favor de su ciudad, perdió su oportunidad de recibir regalos por ello. $\mathrm{Si}$ ayudar, incluso sin obtener nada a cambio, resulta valioso, tanto más lo será hacerlo cuando existe la posibilidad de compensación. En otras palabras, ayudar a los griegos es bueno; ayudarlos y obtener a cambio numerosos premios, mejor.

(7) ov̉ $\underline{\alpha} \rho \underline{\mu o 1} \underline{\delta \circ \kappa \varepsilon ́ \varepsilon 1 ~ \mu v ́ \theta o t o ~} \tau \varepsilon \lambda \varepsilon v \tau \grave{\eta}$

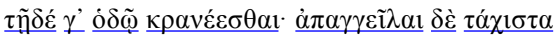

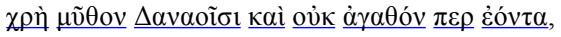

oï $\underline{\pi 0 v} \underline{v \tilde{v} v} \underline{\varepsilon ̈ \alpha \tau \alpha 1} \underline{\pi 0 \tau 1 \delta \varepsilon ́ \gamma \mu \varepsilon v o l}$.

En efecto, no me parece que se cumpla por este camino

el propósito del discurso, y es necesario comunicar lo más pronto posible

la respuesta a los dánaos, incluso no siendo muy buena;

quizás ellos ahora se hallan esperando.

(Il. IX, 625-628)

En su breve discurso, Áyax reconoce la ineficacia de los discursos de Odiseo y Fénix para convencer a Aquiles. El hecho de que afirme que $\underline{\tau} \tilde{\tilde{\delta}} \delta \dot{\delta} \delta \tilde{\omega}$ (por este camino) no se llega al propósito de los discursos evidencia, en el nivel léxico, que la metáfora "UNA DISCUSIÓN (/ ARGUMENTO) ES UN VIAJE" (Lakoff, y Johnson, 2001: 130; mayúscula del original) es parte de la cosmovisión griega desde esta temprana época y, en gran medida, sustenta la propuesta de análisis de marcadores del discurso como elementos que interrelaciones distintos segmentos textuales a través de ese recorrido.

En esta cita, el uso del conector es similar al ejemplo previo: la situación es crítica, por tanto, conviene llevar la respuesta de forma expedita, si esta es positiva, pues los griegos han de estar ansiosos por escucharla; pero especialmente si es negativa, dado que deberán pensar en una solución alternativa.

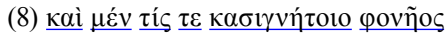

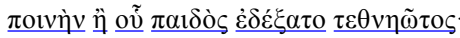

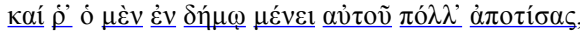

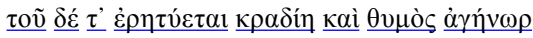

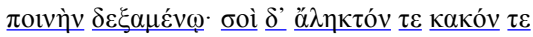

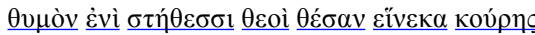

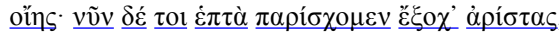

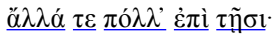

pues incluso cualquiera,

habiendo muerto su hermano o su hijo, recibe compensación del asesino;

y entonces él permanece en su propio pueblo, habiendo pagado mucho,

y el corazón y el ánimo altivo del que recibió la compensación

se calman; pero a ti un ánimo malvado y obstinado

los dioses te pusieron en el pecho, por causa de una sola joven,

pese a que ahora te ofrecemos siete mujeres extraordinarias

y muchas otras cosas además de estas.

(Il. IX, 632-639) 
Una vez más es el discurso de Áyax la fuente para el estudio de este conector. Los dos argumentos, en este caso, son la pérdida de una compañera arrebatada y la pérdida de un hijo o un hermano muerto. Este posee un valor mayor por al menos dos razones: en primer lugar, la muerte es una pérdida permanente, mientras que la acción de tomarla es solo temporal; en

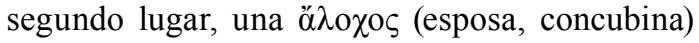
no representa lo mismo que un pariente de sangre. Si cualquier persona acepta compensación por esta pérdida mayor, Aquiles debería aceptarla por su pérdida menor.

\section{De base causal}

\subsection{Finales}

\subsection{1. $̋ \omega \varsigma$ (para que)}

En lengua griega, ö $\pi \omega \varsigma$ (Pabón, 1999: 431) funciona como adverbio (como) o como conjunción final (para que). Con este valor, aparece en el discurso de Odiseo. En la siguiente cita (9), dicho personaje, célebre por su facilidad de palabra, exhorta a Aquiles a la reflexión con el imperativo $\varphi \rho \alpha ́ \zeta ̨ v$ (reflexiona). El llamado a la reflexión tiene como objetivo procurar el provecho para el bando griego. Sin Aquiles el desastre es inminente; con Aquiles, previsible, si $\underline{\text { se actúa con rapidez. }}$

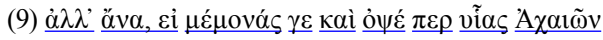

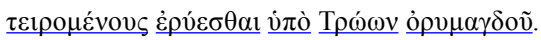

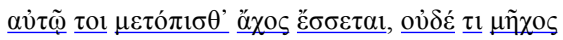

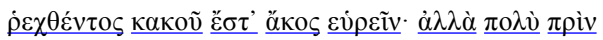

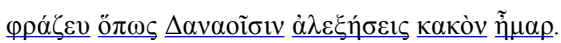

Pero, ¡vamos! Si ya es demasiado tarde, aunque te propongas

sacar del tumulto a los hijos de los aqueos que sufren a causa de los troyanos,

tú mismo después sentirás pena, y no hay ningún modo de encontrar remedio contra un mal sucedido; en cambio, antes

reflexiona, para que apartes de los dánaos el día fatal.

(Il. IX, 247-251)

\subsection{2. $\omega \varsigma$ (de modo que)}

Con al menos siete sentidos distintos, ஸ́ (Pabón, 1999: 655) es una las palabras más versátiles del griego: adverbio de modo (así), adverbio de comparación (como), conjunción completiva (que), conjunción final (para que), conjunción consecutiva (de modo que), conjunción causal (porque) y conjunción temporal (cuando). De ella se vale Aquiles en su primera respuesta, dirigida precisamente a Odiseo, a la cual pertenece la siguiente cita (10). La necesidad de responder a Agamenón se conecta con la conveniencia de compartir su postura con los embajadores por medio de este conector final. El sentido es final porque el verbo

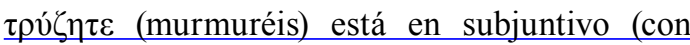
sentido consecutivo debería ir acompañado de un verbo en indicativo).

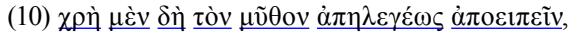

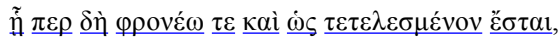

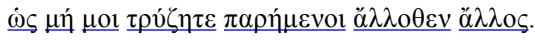

es preciso que ya francamente te dé a conocer mi resolución,

en la que ciertamente ahora pienso, tal como será cumplida,

de modo que, estando sentados junto a mí, no murmuréis cada uno desde su sitio.

(I1. IX, 309-311)

\subsection{Causativos}

2.2.1. $\gamma \alpha \dot{\rho} \rho$ (pues) 


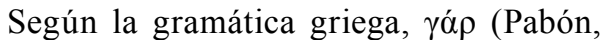
1999: 116) es una conjunción causal (pues), explicativa (a saber) o de certeza (en efecto). Empleada para introducir un paréntesis en la frase, aparece en nueve ejemplos del corpus (11-19).

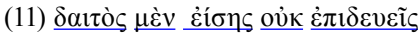

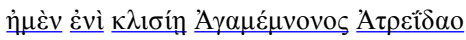

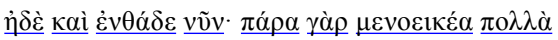

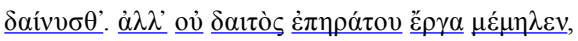

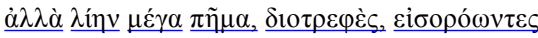

$\underline{\delta \varepsilon i ́ \delta \mu \varepsilon v} \cdot \underline{\dot{\varepsilon} v} \underline{\delta o u \tilde{\eta}} \underline{\delta \dot{\varepsilon}} \underline{\sigma \alpha \omega \sigma \varepsilon \dot{\mu} \mu \varepsilon v} \underline{\grave{g}} \underline{\dot{\alpha} \pi 0 \lambda \varepsilon \dot{\varepsilon} \sigma \theta \alpha \mathrm{l}}$

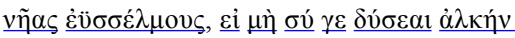

No estamos necesitados de banquete, equitativo

tanto en la tienda del Atrida Agamenón

como también aquí y ahora, pues cerca tenéis muy abundante comida;

pero no nos preocupan los trabajos del amado banquete,

sino que, contemplando una desgracia muy grande, 'vástago de Zeus',

tememos: en la duda de si se salvarán o se destruirán

las naves bien provistas de bancos, si tú, por lo menos, no te revistes de valor.

\section{(Il. IX, 225-231)}

Con una preterición, Odiseo comienza su discurso diciendo para qué no han venido a la tienda de Aquiles. Su motivación no es el banquete, lo que se justifica aclarando que este es abundante, tanto para Agamenón como para Aquiles.

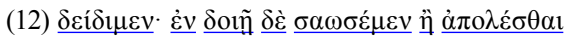

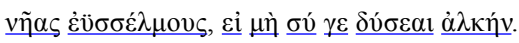

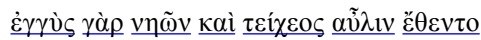

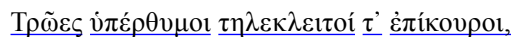

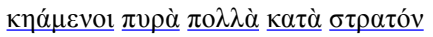

tememos: en la duda de si se salvarán o se destruirán

las naves bien provistas de bancos para remeros, si tú no te revistes de valor,

pues cerca de las naves y de la muralla establecieron el campamento

los altivos troyanos y sus célebres aliados,

encendiendo muchas piras a lo largo del campamento.

$$
\text { (Il. IX, 230-234) }
$$

Esta cita, tomada igualmente del discurso de Odiseo, continúa la argumentación, al afirmar para qué han venido: necesitan ayuda porque tienen miedo y tienen miedo porque los troyanos están muy cerca del campamento griego. De acuerdo con texto de la Ilíada, se entiende bien la preocupación, dado que los griegos, emplazados entre el mar y los enemigos, realmente se encuentran en una posición desventajosa.

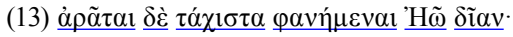

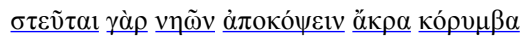

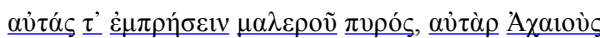

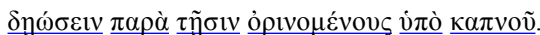

Y pide que lo más pronto posible se muestre la divina Aurora,

pues amenaza con cortar los elevados emblemas de las naves

y con quemar estas con devastador fuego; luego, junto a ellas,

con despedazar a los aqueos que huyen por el humo.

(Il. IX, 240-243) 
Siempre en el discurso de Odiseo, se afirma que Héctor (tal es el sujeto del verbo $\underline{\alpha} \rho \tilde{\alpha} \tau \alpha 1$, 'pide') pide la llegada de la Aurora y que amenaza con dañar a los griegos. Para comprender la relación causal entre estas dos ideas, es preciso tener en cuenta que la Aurora (tanto el fenómeno atmosférico como la divinidad homónima) marca el inicio de la batalla. En una época en que la iluminación artificial, si bien no es inexistente, es más bien simple, la guerra se lleva a cabo durante los días y se suspende durante las noches. El cese de actividades militares resulta provechoso para aquellos en una situación mala, pero no así para aquellos en mejores condiciones. Héctor, cuyo ejército lleva la delantera en la lucha, anhela el amanecer para poder continuar la batalla en la que, de momento, está triunfando.

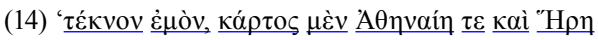

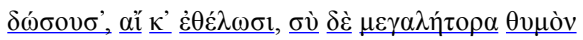

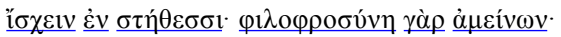

"Hijo mío, Atenea y Hera, si quieren, te darán fuerza;

tú contén en tu pecho tu ánimo altanero,

pues la benevolencia es lo mejor."

(Il. IX, 254-256)

En un discurso dentro del discurso, Odiseo refiere las supuestas palabras de Peleo a su hijo Aquiles. El conector obedece a la misma relación causal que en los ejemplos anteriores: como parte de una sinécdoque, contener el ánimo y preferir la benevolencia se ponen en relación. El ejemplo es interesante, debido a que la propia justificación es objeto de una justificación ulterior. Así, el héroe debe optar por $\varphi 1 \lambda$ $\lambda \rho \rho o \sigma u ́ v \eta$ (benevolencia), no solo porque es lo mejor en el ámbito humano, sino también porque el resultado final de las acciones depende, en última instancia, de la voluntad divina.

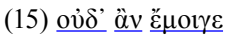

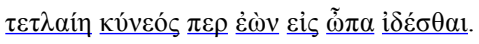

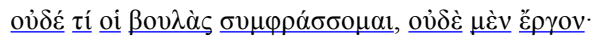

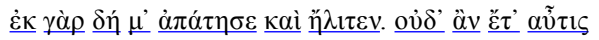

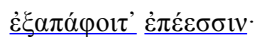

ni a mí él,

siendo un cínico, se atrevería a verme a la cara,

ni yo con él compartiré para nada consejos o esfuerzo,

pues, me engañó y me injurió, pero ya no podrá engañarme

de nuevo con sus palabras.

(Il. IX, 372-375)

En su primera respuesta, Aquiles sostiene, con un argumento de los llamados de reciprocidad (aquellos "basados en los nexos entre el antecedente y el consecuente de una misma relación, parecen, más que cualquier otro argumento cuasi lógico, ser a la vez formales y estar fundamentados en la naturaleza de las cosas"; Perelman y Olbrechts-Tyteca, 1994: 344), que la intención de permanecer alejado de Agamenón se debe al engaño. Estando cerca lo engañó, pero estando lejos no podrá hacerlo.

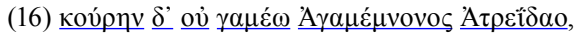

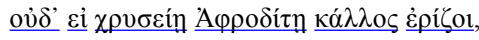

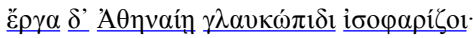

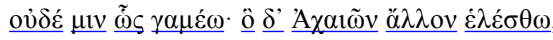

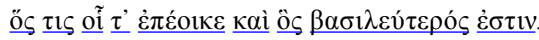

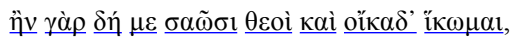

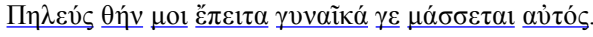

Y no me casaré con la hija del Atrida Agamenón,

ni siquiera si rivalizara en belleza con la áurea Afrodita 
y se igualara en labores con Atenea, de ojos de lechuza;

ni así me casaré con ella, que él entre los aqueos otro tome,

cualquiera que le convenga y que sea más rey que yo,

pues, si los dioses me salvan y llego a casa,

entonces el propio Peleo sin duda me buscará una esposa.

(Il. IX, 388-394)

Todavía como parte de la primera respuesta, Aquiles rechaza la oferta de Agamenón de darle a una de sus propias hijas en matrimonio. El conector explicita el vínculo causal entre la negativa al matrimonio concertado por Agamenón y la posibilidad de uno concertado por Peleo. Aquiles no necesita a la hija de Agamenón, ni aunque sea más laboriosa que Atenea (diosa del tejido) o más bella que Afrodita (diosa del amor). Las comparaciones, de carácter hiperbólico, son particularmente significativas si se considera el hecho de que tejido, belleza y fidelidad son las cualidades esenciales de la

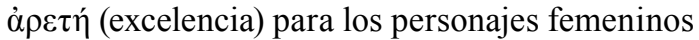
en la épica homérica. Con todo, Aquiles tiene a Peleo, su padre, quien puede conseguirle una esposa.

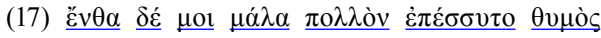
$\dot{\alpha} \gamma \eta \dot{\eta} \omega \omega \rho$

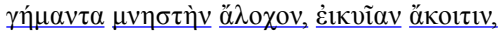

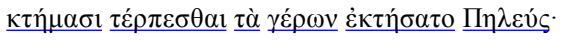

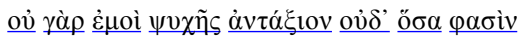

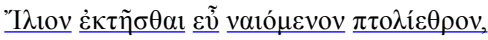

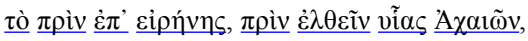

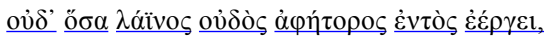

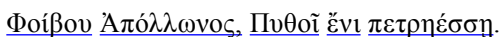

Allí mi valiente ánimo, habiendo tomado esposa legítima,

compañera conveniente, mucho se afanaba en deleitarse

con las riquezas que el anciano Peleo se había procurado,

pues, para mí no es equivalente a la vida

ni cuanto dicen que tenía Ilión, la bien poblada,

en otro tiempo, en período de paz, antes de que llegaran los hijos de los aqueos;

ni cuanto el umbral de piedra del lanzador de flechas,

de Febo Apolo, encierra dentro en la rocosa Pito.

(Il. IX, 398-405)

El deíctico $\underline{\varepsilon} v \theta \alpha$ (allí) se refiere a Ftía, patria de Aquiles, donde, antes de la guerra de Troya, Aquiles disfrutaba las riquezas de Peleo, y donde, después de ella, espera poder volver a disfrutarlas. La vida vale más que las riquezas: ese el tema central de la respuesta de Aquiles. El héroe quiere regresar porque allí estaba su vida, y allí también habría de estar su muerte. En griego, hay un juego de palabras (Nagy, 1999: 185) entre ó $\varphi \theta \imath \tau o \varsigma$ (inmortal) y $\Phi \theta$ ín (Ftía, ¿muerte?), ambas derivadas de la raíz indoeuropea $d{ }^{w}{ }^{w} h e i-$, 'morir' (Watkins, 2000: 20).

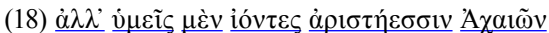

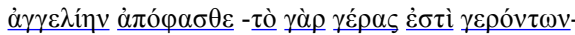

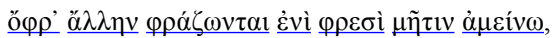

Ahora bien, vosotros, yéndoos, declarad a los mejores de los aqueos

este mensaje, pues esto es dignidad de los ancianos, para que tracen en sus mientes otro proyecto mejor,

(Il. IX, 421-423) 
Desde su primera respuesta, Aquiles pide a los embajadores trasmitir su mensaje. La

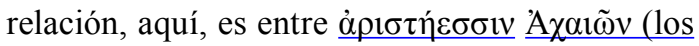

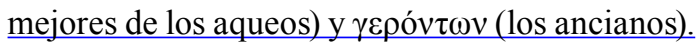
Mientras que todos los griegos en el ejército que ataca Troya son parte de la asamblea, solo un selecto grupo lo son del consejo. Tanto "los mejores" como "los ancianos" remiten a este último grupo. Es dignidad de los miembros del consejo decidir cómo obrar en relación con un tema particular.

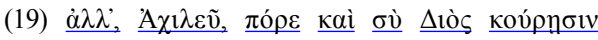
$\underline{\varepsilon} \pi \varepsilon \sigma \theta \alpha \mathrm{l}$

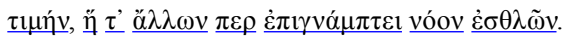

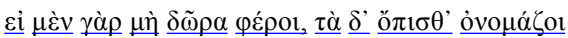

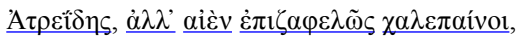

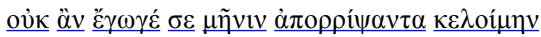

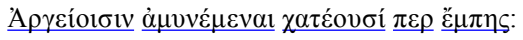

Pero, Aquiles, procura también tú que a las hijas de Zeus acompañe

el honor, el cual, pese a todo, doblega el ánimo de los otros nobles,

pues, si el Atrida no ofreciera regalos ni prometiera otros después,

sino que siempre se mostrara violentamente contrario,

yo por mi parte no ordenaría que tú, habiendo depuesto la cólera,

ayudaras a los argivos, si bien tienen necesidad:

(Il. IX, 513-518)

En el último de estos ejemplos, Fénix relata la historia de las $\Lambda$ i $\alpha$ í (Súplicas), unas

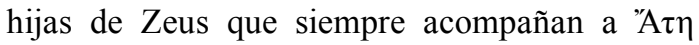
(Ceguera). En el nombre de esta divinidad subyace la metáfora "ENTENDER ES VER" (Lakoff y Johnson, 2001: 87; mayúscula del original): cuando los humanos no ven (sc. no entienden), se equivocan y actúan mal; después, deben pedir perdón si con su accionar erróneo han afectado a otros, es decir, deben suplicar. Así, Agamenón, que antes se erró con la toma de Briseida, ahora se disculpa con el ofrecimiento de regalos; por tanto, Aquiles, en atención a su honor, debería perdonarlo.

\subsection{Consecutivos}

\subsection{1. ǒ $\rho \alpha$ (entonces)}

La partícula ö $\rho \alpha$ (Pabón, 1999: 82) tiene un valor temporal (entonces) e ilativo (entonces). En argumentos, permite introducir la conclusión. Hay dos ejemplos de esto en el corpus (20-21)

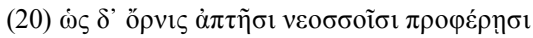

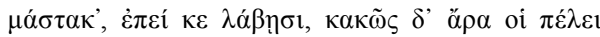
$\alpha$ $\tau \tilde{\eta}$,

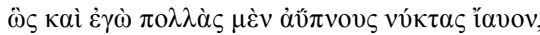

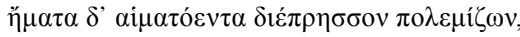

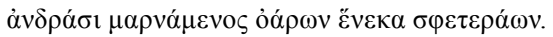

Como el ave que lleva adelante para sus polluelos sin alas

el alimento siempre que se apodera de él, y entonces a ella misma le va mal;

así también yo mismo pasaba muchas noches en vela,

y consumía los sangrientos días guerreando,

batallando con los hombres por causa de sus compañeras.

(Il. IX, 323-327)

Aquiles, en un símil empleado en su primera respuesta, se compara con un ave: así como el ave se preocupa más por los polluelos que por ella, del mismo modo, Aquiles se ha preocupado más por los griegos que por él. 


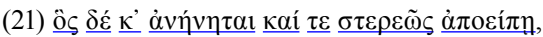

$\underline{\lambda i ́ \sigma \sigma o v \tau \alpha 1} \underline{\delta} \underline{\alpha} \underline{\rho} \alpha \underline{\tau \alpha i} \underline{\gamma \varepsilon} \underline{\Delta i \alpha} \underline{K \rho o v i ́ \omega v \alpha} \underline{\kappa 10 \tilde{\sigma} \sigma 1}$

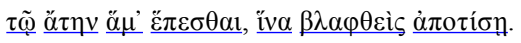

quien las rechaza y con fuerza las repudia,

ellas, entonces, marchando suplican al Cronida

Zeus que la Ceguera

al instante lo acompañe, para que, habiéndolo entorpecido, lo haga pagar.

(Il. IX, 510-512)

En el relato de las Súplicas que hace Fénix, se explica el accionar de estas divinidades: si alguien rechaza a las Súplicas, ellas procuran la venganza de Zeus; alguien rechaza a las Súplicas; entonces, ellas procuran la venganza de Zeus.

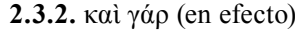

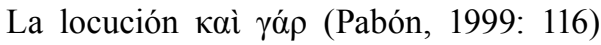
es de carácter explicativo. El corpus brinda solamente un ejemplo (22). En la historia de Meleagro que narra Fénix, se relaciona la muerte de los guerreros de ambos bandos (etolos y curetes) con la cólera de la diosa Ártemis que resulta en el envío del jabalí. Si bien morían por causas distintas (los etolos, por la defensa de Calidón; los curetes por el ataque de Calidón), ambos bandos tenían mayor número de muertes debido a la intervención divina.

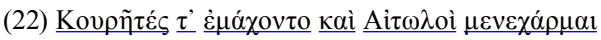

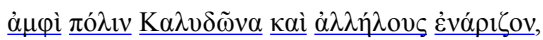

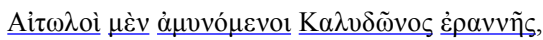

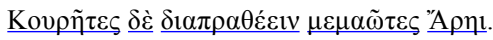

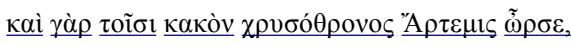

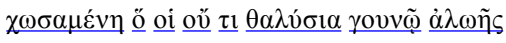

Oiveùs $\underline{\rho} \underline{\varepsilon} \xi^{\prime}$.
Los curetes y los etolos, firmes en el combate, luchaban

en torno a la ciudad de Calidón y se mataban unos a otros,

los etolos ayudando a Calidón, la amable,

los curetes intentando por Ares devastarla;

en efecto, les provocó un mal Ártemis, la de trono dorado,

estando enojada porque Eneo no le ofreció las primicias en un promontorio

de la viña.

(Il. IX, 529-535)

\section{Contraargumentativos}

\subsection{Los que introducen un contraargumento} débil

\subsection{1. cỉ kaí (aunque)}

La locución griega kaì cỉ o cỉ kaí (Pabón, 1999: 319) significa "aun si", "aun cuando", "aunque". Con este sentido, se encuentra en dos ejemplos del corpus (23-24).

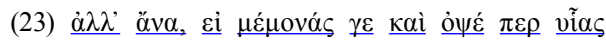
$\underline{\mathrm{A} \chi \alpha \iota \tilde{\omega} \mathrm{v}}$

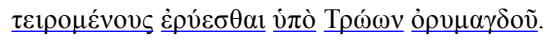

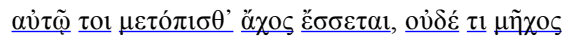

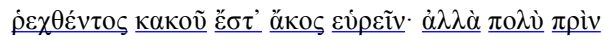

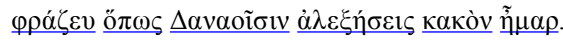

Pero, ¡vamos! Si ya es demasiado tarde, aunque te propongas

sacar del tumulto a los hijos de los aqueos que sufren a causa de los troyanos,

tú mismo después sentirás pena, y no hay ningún modo 
de encontrar remedio contra un mal sucedido; en cambio, antes

reflexiona, para que apartes de los dánaos el día fatal.

\section{(Il. IX, 247-251)}

La cita (23) ya fue analizada en (9) como parte de los conectores de base causal. No obstante, el discurso de Odiseo presenta también este conector contraargumentativo, mediante el cual la decisión correcta en el momento incorrecto se muestra como inferior en valor: lo mejor sería la opinión acertada en el momento oportuno.

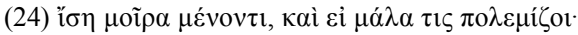

La misma parte tiene, aunque permanezca en casa o guerree mucho.

(Il. IX, 318)

En su primera respuesta, Aquiles ofrece este brevísimo argumento en contra de la $\alpha \rho \varepsilon \tau \eta ́$ (excelencia) heroica. La $\mu$ oĩ $\alpha$ (destino), que en griego designa la parte de vida que le correspondido en suerte a cada ser humano, es igual para quien se apega al ideal heroico y para quien no lo hace. En una cultura de la vergüenza (Dodds, 1986: 39-70), como la Grecia homérica, en la cual lo más importante para la valoración individual es la valoración colectiva, si el destino humano es siempre la muerte, y si en la muerte no hay distinción entre la vida heroica y la que no fue, ¿para qué ser un héroe? Tal es, precisamente, el cuestionamiento último de Aquiles en la Ilíada.

\subsection{2. ov̉ $\delta$ ' $\varepsilon \mathfrak{i}$ (ni siquiera si)}

Esta locución se forma con la unión de la conjunción condicional عỉ (si) y la conjunción copulativa ov̉ó́ (ni), que, a su vez, resulta de la combinación del adverbio de negación ov̉ (no) con la partícula $\delta \varepsilon \dot{\varepsilon}$ con valor copulativo (y). Se hallaron tres ejemplos en el texto (25-27).

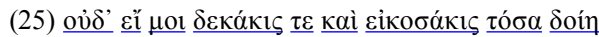

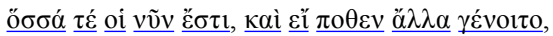

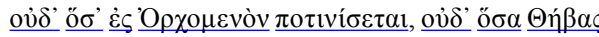

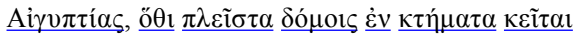

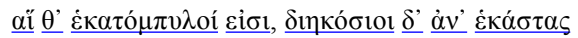

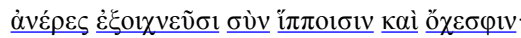

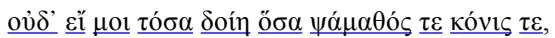

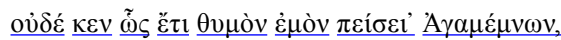

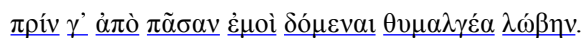

Ni siquiera si diez veces, o incluso veinte veces, tanto me diera

cuanto ahora tiene; si de alguna parte otras cosas aparecieran:

cuanto ingresa a Orcómeno, cuanto a la egipcia Tebas,

donde yacen numerosas riquezas en las casas,

la ciudad de las cien puertas, a través de cada una de las cuales

salen doscientos hombres con caballos y carros;

ni siquiera si tanto me diera cuanto hay de arena y de polvo;

ni aún así podría Agamenón persuadir mi ánimo,

hasta que no me compense por toda la afrenta que me aflige el ánimo.

(Il. IX, 379-387)

La cita (25) se analizó en (4), como parte de los conectores aditivos. El contexto era la primera respuesta de Aquiles, en la que el héroe rechaza una compensación material para una ofensa de carácter inmaterial. El contraargumento pone en evidencia la debilidad de la propuesta: el número 
que ofrece no alcanza porque ningún número alcanzaría. Tal es el sentido de la hipérbole sobre los granos de arena o de polvo.

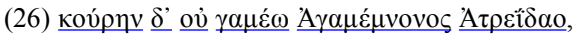

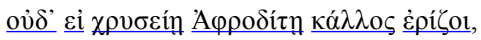

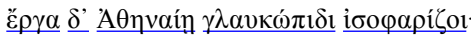

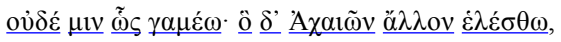

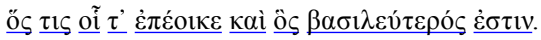

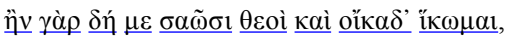

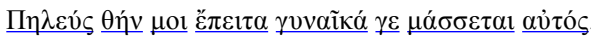

Y no me casaría con la hija del Atrida Agamenón,

ni siquiera si rivalizara en belleza con la áurea Afrodita

y se igualara en labores con Atenea, de ojos de lechuza;

ni así me casaré con ella, que él entre los aqueos otro tome,

cualquiera que le convenga y que sea más rey que yo,

pues, si los dioses me salvan y llego a casa,

entonces el propio Peleo sin duda me buscará una esposa.

(Il. IX, 388-394)

La cita (26), igualmente, ha sido objeto de análisis en (16), a propósito de los conectores de base causal. En esta ocasión, la respuesta negativa de Aquiles enfatiza la debilidad del argumento de Agamenón. Según este, una hija suya supera a Briseida; según aquel, una diosa no supera a Briseida. Mediante un argumento por ridículo ("admitir momentáneamente una tesis opuesta a la que se quiere defender, en desarrollar sus consecuencias, en mostrar su incompatibilidad con aquello en lo que se cree y en pasar de ahí a la verdad de la tesis que se sostiene"; Perelman y Olbrechts-Tyteca, 1994: 324), admite la posibilidad de que dicha mujer pudiera emular a las diosas. El escenario hipotético no basta, entonces, tampoco basta la situación presente.

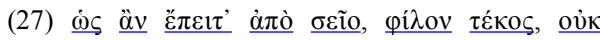
$\dot{\varepsilon} \theta \dot{\lambda} \lambda$ oı $\mu \mathrm{t}$

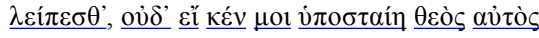

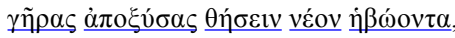

Entonces, así lejos de ti no querría, 'hijo querido', quedarme,

ni siquiera si un propio dios me prometiera,

habiéndome quitado la vejez, ponerme joven en la plenitud de la edad.

(Il. IX, 444-446)

Este ejemplo procede del discurso de Fénix. El conector evidencia la relación entre dos aspectos deseados: que el padre tenga la compañía del hijo (propiamente, Peleo es el padre de Aquiles; Fénix, el preceptor que ha asumido un rol paterno) y que el viejo tenga el don de la juventud. Para la mentalidad griega, la vejez es algo negativo, en tanto conlleva el abandono de aquello considerado como positivo: belleza física, destreza guerrera, capacidad amatoria. En su argumentación, Fénix explicita la superioridad del argumento familiar en relación con el etario.

\subsection{3. $\gamma \varepsilon$ (por lo menos)}

La partícula enclítica $\gamma \varepsilon$ (Pabón, 1999: 116) puede traducirse como "al menos", "por lo menos", "de todos modos", "de cierto", "por cierto", "exactamente". Las cuatro citas que se ofrecen a continuación (28-31) ejemplifican el uso literario de dicho conector.

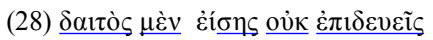

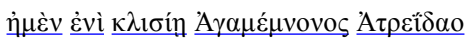




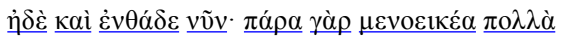

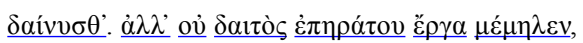

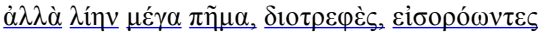

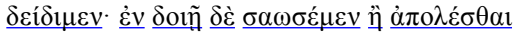

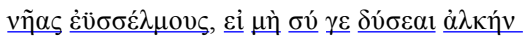

No estamos necesitados de banquete, equitativo

tanto en la tienda del Atrida Agamenón

como también aquí y ahora, pues cerca tenéis muy abundante comida;

pero no nos preocupan los trabajos del amado banquete,

sino que, contemplando una desgracia muy grande, 'vástago de Zeus',

tememos: en la duda de si se salvarán o se destruirán las naves bien provistas de bancos, si tú, por lo menos, no te revistes de valor.

$$
\text { (Il. IX, 225-231) }
$$

La cita (28) fue tratada en (11), por poseer también un conector de base causal. Procede del primer discurso del primer embajador: Odiseo. La tentativa inicial para convencer al héroe consiste en apelar a su heroísmo. Lo mínimo que podría hacer Aquiles es mostrar valor.

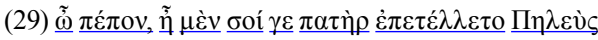

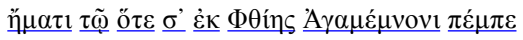

¡Oh, ‘dulce amigo'! Ciertamente, por lo menos tu padre Peleo te lo ordenaba

aquel día, cuando te enviaba desde Ftía ante Agamenón.

(Il. IX, 252-253)
En el fragmento precedente, Odiseo, a través del mismo procedimiento retórico, afirma ahora que lo mínimo que podría hacer Aquiles es obedecer a su padre, quien le había aconsejado pelear por los griegos.

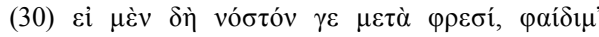
A $\chi \imath \lambda \lambda \varepsilon \tilde{v}$,

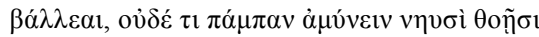

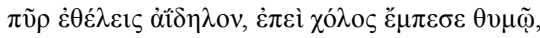

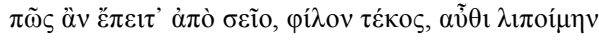

oิ̃os;

Aún si en tu mente, por lo menos, pones el regreso, 'ilustre Aquiles',

y en absoluto quieres alejar de las naves

el enceguecedor fuego, pues la cólera se apoderó de tu ánimo,

entonces, ¿cómo podría, 'hijo querido', quedarme solo aquí

lejos de ti?,

(Il. IX, 434-438)

En su discurso, Fénix distingue, en la afirmación de Aquiles de regresar a Ftía, entre el regreso propiamente (en la realidad) y la intención de regreso (en la mente). Este sería, argumentativamente, más débil que aquel.

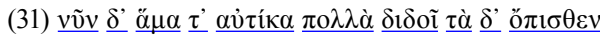
i் $\tilde{\varepsilon} \sigma \tau \eta$,

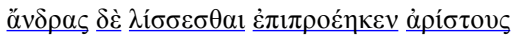

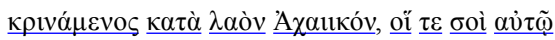

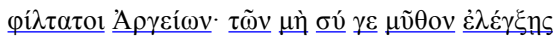

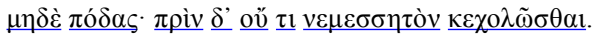

Pero ahora al punto te da muchas cosas y otras después te ha prometido, 
y envió a suplicar a los mejores hombres,

escogidos entre el ejército aqueo, a quienes tú mismo tienes

por los más queridos de los argivos: de ellos no desprecies tú, por lo menos,

el discurso ni los pies; pues haber estado irritado antes no es algo indignante.

(Il. IX, 519-523)

Nuevamente es Fénix quien recurre al conector. En una metonimia, separa a los embajadores propiamente, cuya acogida es de mayor relevancia, de su discurso $(\mu v 0$ ov) y de sus pies $(\pi$ ó $\delta \alpha$ s). Lo que llevan y el modo en que lo llevan es lo mínimo a lo que cabría prestar atención en cuanto a los embajadores.

3.2. Los que introducen un contraargumento fuerte:

\subsection{1. $\alpha \lambda \lambda \dot{\alpha}$ (pero)}

Los últimos dos ejemplos (32-33) utilizan la conjunción $\dot{\alpha} \lambda \lambda \alpha$, cuyo sentido (Pabón, 1999: 26-27) puede ser adversativo (pero), de refuerzo (pues bien) o de transición (ahora bien).

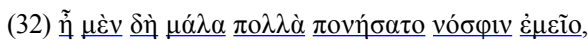

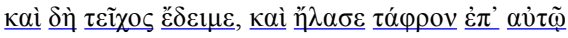

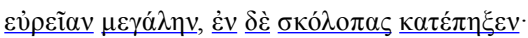

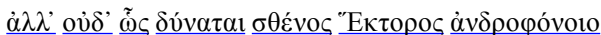

ióx\&ıv.

Ciertamente, lejos de mí sufrió mucho:

construyó un muro, junto a él tendió una fosa

ancha y grande, y en ella clavó estacas;

pero ni aun así es capaz de detener la fuerza de Héctor,

matador de hombres.

(Il. IX, 348-352)
La fuerza de Agamenón queda clara con la mención del muro y la fosa; ahora bien, la mayor fuerza de Héctor se evidencia en el hecho de que todos los esfuerzos de Agamenón por detenerlo han resultado inútiles. El contraargumento de Aquiles sería algo como esto: Agamenón es bueno para enfrentar a Héctor, pero Aquiles es mejor.

$$
\text { (33) } \pi 0 \lambda \lambda \grave{\alpha} \delta^{\prime} \dot{\varepsilon} \tau \alpha i ̃ \rho o t,
$$

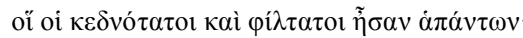

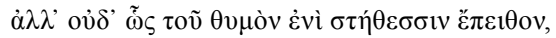

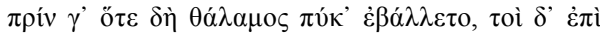
$\pi v ́ \rho \gamma \omega v$

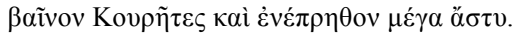

Y mucho le suplicaban los compañeros,

los que él tenía por más fieles y más queridos de todos;

pero ni aun así persuadían el ánimo en su pecho,

sino hasta que ya la habitación con insistencia era asediada, y ellos, los curetes,

sobre las torres avanzaban y quemaban la gran ciudad.

(Il. IX, 585-589)

En el relato sobre Meleagro, Fénix, de algún modo, anticipa el fracaso de la embajada: así como Meleagro no se dejó persuadir por sus compañeros, del mismo modo, Aquiles no cede ante los suyos. El argumento se refiere a la amistad de Meleagro-Aquiles; el contraargumento, a su cólera. En última instancia, $\mu \tilde{\eta} v ı s$ (cólera)

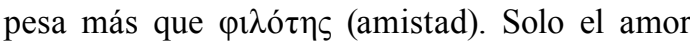
por un ser querido (la esposa Cleopatra para Meleagro, el compañero Patroclo para Aquiles) será suficiente motivo para deponer la cólera. 


\section{Tipología de los conectores en griego antiguo}

Las tres clases propuestas son las siguientes: conectores aditivos, conectores de base causal y conectores contraargumentativos.

Se entiende por conectores aditivos a aquellos que "unen a un miembro discursivo anterior otro con la misma orientación argumentativa... Permiten, de este modo, la inferencia de conclusiones que serían difíciles de lograr si los dos miembros permanecieran independientes" (Martín y Portolés, 2000: 4093) o aquellos con los que "el texto avanza en una misma línea y el locutor manifiesta una misma orientación en la información, añadiendo más elementos, tanto si la línea avanza en sentido afirmativo como negativo" (Calsamiglia y Tusón, 2008: 238). En el corpus trabajado, poseen dos funciones: añadir un argumento de igual valor $\mathrm{y}$ añadir un argumento de mayor valor, de acuerdo con su "fuerza argumentativa" (Martín y Portolés, 2000: 4075).

A su vez, los conectores de base causal incluyen los finales, que "introducen la causa como meta o propósito que se persigue" (Calsamiglia y Tusón, 2008: 238); los causativos, que "introducen la relación de causa entre segmentos textuales" (Calsamiglia y Tusón, 2008: 238); y los consecutivos, que "presentan el miembro del discurso en el que se encuentran como una consecuencia de un miembro anterior" (Martín y Portolés, 2000: 4099) e "introducen la consecuencia entre segmentos textuales" (Calsamiglia y Tusón, 2008: 238).

Por último, conectores contraargumentativos se refiere a aquellos que "vinculan dos miembros del discurso, de tal modo que el segundo se presenta como supresor o atenuador de alguna conclusión que se pudiera obtener del primero" (Martín y Portolés, 2000: 4109) o bien a aquellos con los que "el texto cambia de orientación en sentido contrario al segmento inmediatamente anterior, bien sea de forma total o de forma parcial. La línea argumentativa sufre un quiebro que indica que se abandona la primera orientación para tomar otra" (Calsamiglia y Tusón, 2008: 238). Según los ejemplos considerados, cuentan con dos valores: los que introducen un contraargumento débil y los que introducen un contraargumento fuerte, de manera análoga a los conectores aditivos, según su "fuerza argumentativa" (Martín y Portolés, 2000: 4075).

\section{Conclusiones}

Las conclusiones del estudio son parciales por varias razones. En primer término, si bien se trabajó un texto considerablemente extenso (414 versos), este representa un solo autor y un solo género literario. En segunda instancia, en el texto literario se encontraron solamente 11 conectores, de los 71 que se postularon con base en la gramática griega. En tercer lugar, los 33 ejemplos de dichos conectores no representan sus únicos usos, pues cada uno de ellos puede tener otros sentidos, como parte de argumentaciones o no.

Hechas estas aclaraciones, los resultados son los siguientes: de los 33 conectores identificados, 8 son aditivos (3 añaden un argumento de igual valor; 5 uno de mayor valor); 14 , de base causal (2 finales, 9 causativos y 3 consecutivos); y 11, contraargumentativos ( 9 introducen un contraargumento débil; 2 uno fuerte). Esta distribución pone de manifiesto que, más que a la refutación de los argumentos de sus interlocutores, los oradores dan prioridad a la justificación de sus propios argumentos.

Para los discursos de los embajadores, la extensión aparece correlacionada con la cantidad de conectores, puesto que, a mayor extensión de versos, mayor número de conectores: en el de Áyax (624-642), hay 2; en el de Odiseo (225306), 8; en el de Fénix (434-605), 10. Para las respuestas de Aquiles, se aprecia un contraste notable entre la primera (308-429), que presenta incluso más conectores que los discursos de embajada (13), y las otras dos (segunda, 607-619; tercera, 644-655), que no cuentan con conectores. La explicación de esto estaría en el carácter argumentativo de los discursos: Odiseo (desde la oficialidad), Fénix (desde la familiaridad), Áyax (desde la camaradería) y Aquiles en su primera respuesta (desde su cuestionamiento) ofrecen argumentos para sustentar su punto de vista. 


\section{Notas}

1. Todas las citas griegas proceden de la edición de Murray y Wyatt (1999). Todas las traducciones al español son obra del autor de este trabajo.

\section{Bibliografía}

Berenguer, Jaime. 2002. Gramática griega. Barcelona: Bosch.

Calsamiglia, Helena y Amparo Tusón. 2008. Las cosas del decir. Manual de análisis del discurso. Barcelona: Ariel.

Cerdas, Maricela. 2015. Los marcadores discursivos en la Cistellaria de Plauto. Tesis de Maestría en Lingüistica. San José: Universidad de Costa Rica.

Crespo, Emilio. 2003. La sintaxis griega hoy. Synthesis X: 31-53.

Dodds, Eric. 1986. Los griegos y lo irracional. Madrid: Alianza.

Durán, María. 2000. Las partículas griegas y las funciones de comunicación. Revista Española de Lingüística XXX(1): 45-76.

Escandell, María. 2008. Introducción a la pragmática. Barcelona: Ariel.

Kroone, Carolina. 1998. A Framework for the Description of Latin Discourse Markers. Journal of Pragmatics XXX: 205-223.

Lakoff, George y Mark Johnson. 2001. Metáforas de la vida cotidiana. Madrid: Cátedra.

López, Antonio. 1988. "Homero". En: López, Juan (ed.) Historia de la literatura griega. Madrid: Cátedra.
López, Manuel. 1999. Causa y consecuencia en la poesía romana: un estudio frecuencial de conectores. Florentia lliberritana X: 187-199.

Martín, Isabel. 1993. La función discursiva de la partícula griega $\delta \varepsilon ́$. Habis XXIV: 219-234.

Martín, María y José Portolés. 2000. "Los marcadores del discurso". En: Bosque, Ignacio y Violeta Demonte (dir.) Gramática descriptiva de la lengua española. Volumen 3. Madrid: Espasa.

Murray, A. and William Wyatt. 1999. Iliad. Books 1-12. Cambridge: Harvard University Press.

Nagy, Gregory. 1999. The Best of the Achaeans. Maryland: The Johns Hopkins University Press.

Pabón, José. 1999. Diccionario manual griegoespañol. Barcelona: Vox.

Perelman, Chaïm y Lucie Olbrechts-Tyteca. 1994. Tratado de la argumentación. La nueva retórica. Madrid: Gredos.

Rodríguez, Francisco. 1992. Nueva sintaxis del griego antiguo. Madrid: Gredos.

Van Eemeren, Frans y Rob Grootendorst. 2002. Argumentación, comunicación y falacias: Una perspectiva pragma-dialéctica. Santiago: Ediciones Universidad Católica de Chile.

Watkins, Calvert. 2000. The American Heritage Dictionary of Indo-European Roots. Boston: Houghton Mifflin Company.

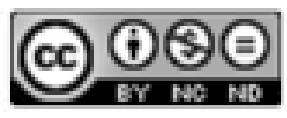

Este obra está bajo una licencia de Creative Commons Reconocimiento-NoComercial-SinObraDerivada 4.0 Internacional. 